\title{
AGENTES NATURAIS E ANTRÓPICOS MODIFICADORES DA QUALIDADE DA ÁGUA E DOS SEDIMENTOS NAS ÁREAS MARGINAIS DA LAGOA DA CONCEIÇÃO, SC
}

\author{
DIAS, B.B ${ }^{1 *}$; PARIZOTTO, B.A.D.M. \& BONETTI, C. \\ 1 - Programa de Pós-Graduação em Geoquímica Ambiental, Universidade Federal Fluminense (UFF), \\ Outeiro de São João Batista, s/n, Centro. Niterói, RJ. 24020-141. \\ 2- Fundação do Meio Ambiente (FATMA). Rua Trajano, 81, Centro. Florianópolis, SC. 88010-010. \\ 3-Departamento de Geociências, Universidade Federal de Santa Catarina. Campus Universitário Trin- \\ dade. Florianópolis, SC. 88040-900. \\ *Corresponding author: diasbb@hotmail.com
}

\begin{abstract}
Dias, B.B; Parizotto, B.A.D.M. \& Bonetti, C. (2014) Agentes naturais e antrópicos modificadores da qualidade da água e dos sedimentos nas áreas marginais da lagoa da conceição, SC. Braz. J. Aquat. Sci. Technol. 18(1):33-43. eISSN 1983-9057. DOI: 10.14210/bjast.v18n1.p33-43 This study investigated water and sediment quality in a subtropical shallow lagoon surrounded by urban occupation. Results were associated to different environmental features and human influence. The analysis revealed highest nitrate and phosphate levels after the summer season and higher concentrations of fecal coliforms after intense precipitation, suggesting an inefficient system of domestic sewage treatment. Statistical analyzes distinguished two most populated areas: area 2-Centrinho presented finer sediments and higher reactive silica concentration than the others, while the area 3-Araças was differenced by the highest total organic matter content in the sediments.
\end{abstract}

Key words: hydrogeochemistry, impacts, subtropical lagoon.

\section{INTRODUÇÃO}

O sistema lagunar funciona dentro de uma matriz biótico-ambiental complexa e vulnerável, sendo passível de desequilíbrio em função de alterações composicionais da coluna d'água e dos sedimentos de fundo (Sierra de Ledo, 1999). Em áreas submetidas às intervenções humanas, as águas estão sujeitas a diversos impactos, sendo aquelas do sistema lêntico mais susceptíveis à carga de substâncias potencialmente poluidoras oriundas de fontes urbanas (Martini et al., 2006).

O lançamento de esgotos domésticos in natura e o desmatamento da vegetação marginal podem ocasionar alterações físicas e químicas nas lagunas, acarretando maior entrada de nutrientes, tais como nitrogênio, fósforo, carbono e de matéria inorgânica particulada (sedimentos terrígenos finos). Estes impactos também estão normalmente associados ao aumento da contaminação bacteriana das águas, comprometendo a balneabilidade, a prática de esportes e a qualidade dos recursos pesqueiros.

Esta situação de degradação ambiental ocorre de modo generalizado em várias lagunas e lagoas brasileiras (Santos et al., 2004; Carloni et al., 2010; Pinto Filho et al., 2012; Cotovicz Jr. et al., 2013). Em relação a qualidade da água da Lagoa da Conceição (Florianópolis, SC), objeto deste trabalho, a crescente urbanização ao seu redor e o aumento do turismo local têm levado nas últimas décadas à alterações no aporte de nutrientes e matéria orgânica para o sistema (Fonseca et al., 2002; Fonseca \& Braga, 2006; Vieira \& Henkes, 2013), submetendo-o ao risco de enriquecimento orgânico e até mesmo eutrofização. Esse processo, uma vez estabelecido, poderá tornar suas águas inadequadas às atividades de pesca, lazer e turismo, ocasionando sérios reflexos na economia local (Martini et al., 2006).

Diversos estudos químicos e ecológicos vêm sendo desenvolvidos na Lagoa da Conceição nas três últimas décadas, definindo as alterações composicionais decorrentes das variações ambientais naturais, intenso crescimento urbano e de intervenções diretas no seu regime hidrodinâmico (Knoppers et al., 1984; Sierra de Ledo, 1999; Fontes \& Abreu, 2009; Fontes et al., 2011).

Dando continuidade a estes estudos, esta pesquisa teve como objetivo avaliar alterações espaciais e temporais em algumas propriedades associadas à qualidade da água e dos sedimentos superficiais das áreas rasas marginais da Lagoa da Conceição sob duas condições distintas de precipitação e de aporte de esgotos domésticos.

\section{MATERIAL E MÉTODOS}

\section{Área de estudo}

A Lagoa da Conceição localiza-se na costa centro-leste da Ilha de Santa Catarina, entre $27^{\circ} 34^{\prime} S$ 
e $48^{\circ} 27^{\prime} \mathrm{W}$. Conceitualmente, trata-se de uma laguna por estar disposta paralelamente a linha de costa, separada do oceano por uma barreira arenosa e por possuir uma ligação de fluxo e refluxo com o mar (Kjerfve, 1994), denominada localmente como Canal da Barra.

Com um formato alongado, a Lagoa da Conceição é caracterizada como uma laguna estrangulada ou semi-fechada, possuindo uma área de 19,2km² e um volume estimado de $40 \times 106 \mathrm{~m}^{3}$ (Knoppers et al., 1984). Seu eixo de maior comprimento chega a 13,5km no sentido Norte-Sul (Assumpção et al., 1981; Knoppers et al., 1984; Odebrecht \& Gomes, 1987) e sua profundidade é variável. Extensos bancos arenosos com profundidades inferiores a $1 \mathrm{~m}$ dominam suas margens e contrapõem-se com canais de circulação estreitos e profundos (com até $8 \mathrm{~m}$ de profundidade), associados à proximidade do embasamento cristalino. Tomando como base as características fisiográficas, alguns autores têm adotado uma proposta de compartimentação deste corpo lagunar em três subsistemas: Norte, Central e Sul (Knoppers et al., 1984; Fonseca et al., 2002).

\section{Procedimentos amostrais}

Para o presente estudo, foram realizadas duas campanhas de coleta nas áreas marginais rasas da Lagoa da Conceição, nos dias 27/11/2008 e 11/03/2009. A primeira campanha foi realizada antes do início da temporada turística e após um mês de elevado índice pluviométrico. Já a segunda campanha foi realizada logo após o final da temporada, sob menor influência das águas pluviais e maior volume de esgotos domésticos.

A malha amostral foi definida abrangendo cinco subáreas (ou subunidades amostrais), todas elas localizadas em profundidades inferiores a $2 \mathrm{~m}$ e com substrato arenoso (Figura 1). A disposição destas subáreas foi definida buscando-se representar diferentes condições da dinâmica lagunar das áreas rasas e do gradiente de ocupação urbana. Assim temos:

1-Canto da Lagoa: localizada no subsistema Sul, com restrita circulação de águas marinhas, próxima ao aporte de drenagem pluvial difuso;

2-Centrinho: localizada também no subsistema Sul e sujeita a moderado confinamento marinho, mas

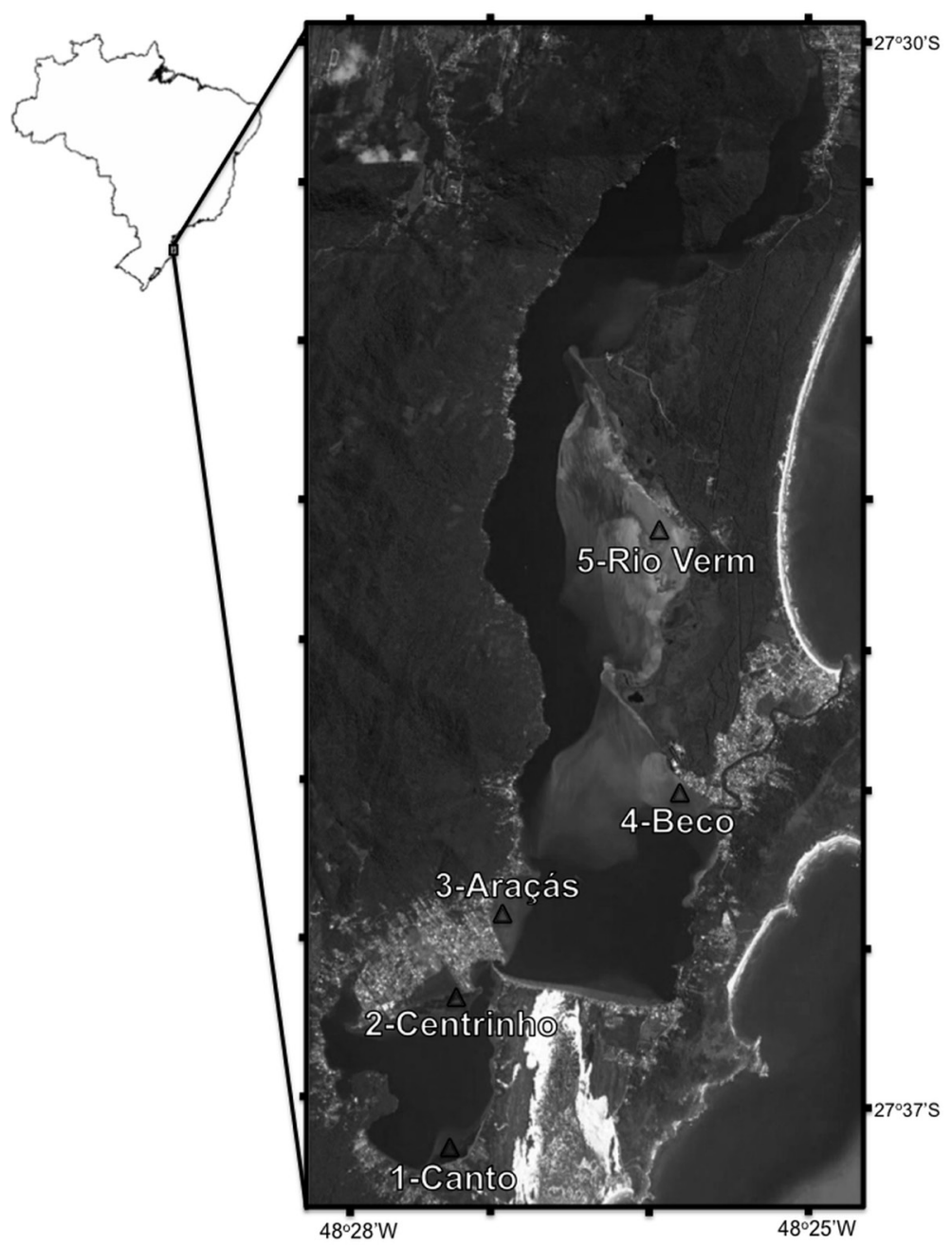

Figura 1 - Localização geográfica da Lagoa da Conceição com a indicação das subáreas das áreas rasas marginais. 
sob forte influência das ondas geradas pelo vento Sul. É o local mais densamente urbanizado;

3-Araçás: localizada no subsistema Central e sujeita à maior hidrodinâmica, sobretudo sob condição de vento Nordeste. Também possui margens densamente urbanizadas e sofre a influência de drenagem continental;

4-Beco dos Coroas: subárea mais próxima do canal de comunicação com as águas marinhas, apresentando o menor grau de confinamento. Também está sujeita à forte hidrodinâmica e embora suas margens sejam urbanizadas, a densidade da ocupação é baixa;

5-Rio Vermelho: no subsistema Norte, encontrase sujeita à maior influência de aporte fluvial e é a única que não possui suas margens ocupadas.

Em cada uma dessas subáreas foram posicionadas três estações equidistantes em $10 \mathrm{~m}$ e dispostas de maneira triangular. Em cada estação foram coletadas amostras do sedimento superficial (para as análises sedimentológicas e geoquímicas) e duas amostras de água (uma na coluna d'água - entre $10 \mathrm{e}$ $20 \mathrm{~cm}$ de profundidade - e outra da água de percolação do sedimento). Para esta última foi utilizado um cano de PVC de $150 \mathrm{~mm}$ de diâmetro e $1 \mathrm{~m}$ de altura, com tampa. Este foi submerso e enterrado no sedimento até uma profundidade de $10 \mathrm{~cm}$; em seguida, a tampa foi retirada e a água de percolação do sedimento emergiu gradativamente, possibilitando assim a sua coleta com o auxílio de pipeta volumétrica de $50 \mathrm{~mL}$. As amostras de água foram subdivididas em três frações destinadas, respectivamente, às análises físicoquímicas, de nutrientes e microbiológicas. Assim, 60 amostras foram obtidas (seis amostras em cada uma das cinco subáreas, em duas campanhas amostrais distintas) para cada variável hidroquímica analisada.

\section{Procedimentos Analíticos}

As variáveis físico-químicas (salinidade, temperatura, $\mathrm{pH}$ e oxigênio dissolvido) foram determinadas diretamente em campo, utilizando sonda multiparâmetro YSI-556MPS.

As amostras destinadas a análise dos nutrientes inorgânicos dissolvidos - nitrogênio amoniacal (íon amônio $\left.\mathrm{NH}_{4}^{+}\right)$, nitrito $\left(\mathrm{NO}_{2}^{-}\right)$, nitrato $\left(\mathrm{NO}_{3}{ }^{-}\right)$, sílica reativa (formas mono e dímeras do $\mathrm{H}_{4} \mathrm{SiO}_{4}$ ) e ortofosfato (íons $\mathrm{PO}_{4}{ }^{3-}, \mathrm{HPO}_{4}{ }^{2-}$ e $\mathrm{H}_{2} \mathrm{PO}^{4-}$ ) - foram imediatamente filtradas em membranas de celulose Whatman de porosidade $0,45 \mu \mathrm{m}$ e mantidas congeladas até 0 momento da análise.

Nas análises de nutrientes foram determinados os teores de nitrito, sílica reativa, ortofosfato (Aminot \& Chaussepied, 1983; Baumgarten et al., 1996; Niencheski et al., 2006), nitrato através do método colorimétrico (Fries, 1971) e nitrogênio amoniacal (Koroleff, 1969). O procedimento metodo- lógico baseou-se em métodos espectrofotométricos (Baumgarten et al., 1996; Niencheski et al., 2006), utilizando espectrofotômetro HACH DR5000 (UltravioletaVisível). As amostras foram lidas utilizando cubetas de quartzo de $1 \mathrm{~cm}$ de passo óptico, sendo que os comprimentos de onda utilizados para cada nutriente foram: $630 \mathrm{~nm}$ para $\mathrm{N}-\mathrm{NH}_{4}{ }^{+}, 543 \mathrm{~nm}$ para $\mathrm{N}_{-} \mathrm{NO}_{2}{ }^{-} \mathrm{e}$ $\mathrm{N}-\mathrm{NO}_{3}{ }_{3}^{-}, 810 \mathrm{~nm}$ para Si e $885 \mathrm{~nm}$ para $\mathrm{P}_{-} \mathrm{PO}_{4}{ }^{3-}$. Para o cálculo da concentração das amostras relacionadas às suas absorbâncias foram feitas curvas de calibração, aceitando-se Coeficientes de Determinação $\left(R^{2}\right)$ acima de 0,99 . Foram assim obtidos valores de $\mathrm{R}^{2}=$ 0,9979 para $\mathrm{N}^{-\mathrm{NH}_{4}+}$ (10 pontos), 0,9992 para $\mathrm{N}-\mathrm{NO}_{2}$ (15 pontos) e 0,9940 para $\mathrm{N}^{-N_{3}}{ }_{3}^{-}$(13 pontos), 0,9967 para Si (17 pontos) e 0,9990 para $\mathrm{P}_{-} \mathrm{O}_{4}{ }^{3-}$ (10 pontos).

Para certificação do preparo das soluçõespadrão utilizadas nas diluições para a curva dos nutrientes, foram analisadas também diluições a partir de soluções-padrão compradas no Laboratório Alfakit Ltda.

\section{Procedimentos sedimentológicos e microbiológicos}

Foram determinados os teores de matéria orgânica total presente nos sedimentos superficiais por meio da queima em mufla de $3 \mathrm{~g}$ de sedimento, à temperatura de $550^{\circ} \mathrm{C}$, durante 2 horas (Gross, 1971; Suguio, 1973).

A caracterização granulométrica dos sedimentos foi obtida mediante a técnica de peneiramento. Esta foi realizada utilizando-se uma alíquota de $30 \mathrm{~g}$ de sedimentos previamente secos e sem fragmentos de carbonato biodetrítico. Com auxílio de um agitador Ro-Tap, os sedimentos foram separados durante 15 minutos, em uma torre de peneiras com malhas entre 2,0 e $0,063 \mathrm{~mm}$ dispostas em intervalos regulares de $1 / 2$ phi (Gross, 1971; Suguio, 1973).

Os coliformes totais e fecais foram determinados pela equipe do Laboratório de Microbiologia Aplicada à Aquicultura, do Laboratório de Camarões Marinhos, na Universidade Federal de Santa Catarina. A metodologia utilizada por este laboratório foi a de substrato definido para detectar coliformes fecais nas amostras de água. As amostras positivas para Escherichia coli usam a enzima b-glucoronidase para metabolizar o indicador 4-Metilumbeliferil- $\beta$-DGlucuronide (MUG) e gerar fluorescência sob a luz ultravioleta (UV) com o comprimento de onda de 366 nm. Para a quantificação do Número Mais Provável (NMP) foram utilizadas combinações de poços positivos em séries de cinco poços com diluições da amostra em 0,1; 0,01 e 0,001 mL (FDA, 1984; APHA, 1992). 


\section{Procedimentos estatísticos}

Uma vez verificada a não normalidade das distribuições (mesmo após tentativas de transformação) através do teste de Shapiro-Wilk (W), foram empregados tratamentos estatísticos univariados baseados na técnica da Análise de Variância não paramétrica (teste de Kruskal-Wallis e o teste a posteriori de comparações múltiplas de Dunn) (Zar, 1998). O referido procedimento permitiu a verificação espacial e temporal das variáveis estudadas. A técnica de Análise de Componentes Principais (ACP) foi aplicada sobre duas matrizes de dados (com variáveis físico-químicas, nutrientes e coliformes fecais) previamente transformados em log $(x+1)$ e padronizados (transformados em valores de $z$ ) (Valentin, 2000). Estes procedimentos foram realizados com o auxílio do programa Statistica 12 (Statsoft, 2013) e com auxílio do software Multi Variate Statistical Package ${ }^{\circledR}$ (MVSP; Kovach, 1999).

\section{RESULTADOS}

\section{Características Sedimentológicas}

A distribuição granulométrica dos sedimentos superficiais de fundo apresentou-se de maneira geral homogênea nas cinco subáreas amostrais, com teores de areia entre 99 e 100\%. A classe predominante nas duas campanhas foi areia fina, segundo a classificação de Folk \& Ward (1957). Os grãos variaram de moderadamente a muito bem selecionados e com diâmetro médio entre 1,8 a 2,4 phi. A subárea 2-Centrinho foi a única que apresentou diâmetro médio dos grãos significativamente menores e também a maior porcentagem média de areia fina (média de $85 \pm 6 \%$ ) (Tabela 1).

Já em relação à matéria orgânica total (MOT) depositada nos sedimentos superficiais das áreas rasas, os teores mostraram-se de modo geral baixos, com valores inferiores a $2 \%$ (Tabela 1 ).

\section{Propriedades Físico-Químicas}

Segundo dados meteorológicos fornecidos pela EPAGRI/CIRAM, nos 30 dias anteriores à primeira campanha (novembro de 2008) houve um acúmulo

Tabela 1 - Valores máximos, mínimos e médias dos descritores sedimentológicos analisados em cada subárea da Lagoa da Conceição.

\begin{tabular}{|c|c|c|c|c|c|c|}
\hline \multicolumn{3}{|c|}{ Subárea x campanha } & \multirow{2}{*}{$\begin{array}{c}\begin{array}{c}\text { Matéria } \\
\text { orgânica } \\
(\%)\end{array} \\
0,6\end{array}$} & \multirow{2}{*}{$\begin{array}{c}\begin{array}{c}\text { Diâmetro } \\
\text { médio } \\
\text { (phi) }\end{array} \\
2,1\end{array}$} & \multirow{2}{*}{$\begin{array}{c}\begin{array}{c}\text { Grau de } \\
\text { seleção } \\
\text { (phi) }\end{array} \\
0,5\end{array}$} & \multirow{2}{*}{$\begin{array}{c}\begin{array}{c}\text { Areia } \\
\text { fina } \\
(\%)\end{array} \\
61,0\end{array}$} \\
\hline \multirow{5}{*}{ 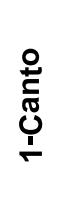 } & \multirow{5}{*}{$\begin{array}{l}\text { Campanha I } \\
\text { (nov 2008) } \\
\text { Campanha II } \\
\text { (mar 2009) }\end{array}$} & Máx. & & & & \\
\hline & & Mín. & 0,5 & 2,1 & 0,4 & 58,6 \\
\hline & & Máx. & 0,6 & 2,1 & 0,5 & 59,9 \\
\hline & & Mín. & 0,5 & 2,0 & 0,4 & 49,1 \\
\hline & & Média & 0,6 & 2,1 & 0,5 & 56,7 \\
\hline \multirow{5}{*}{ 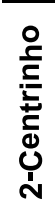 } & \multirow{5}{*}{$\begin{array}{l}\text { Campanha I } \\
\text { (nov 2008) } \\
\text { Campanha II } \\
\text { (mar 2009) }\end{array}$} & Máx. & 0,6 & 2,4 & 0,4 & 92,0 \\
\hline & & Mín. & 0,3 & 2,3 & 0,3 & 78,8 \\
\hline & & Máx. & 0,5 & 2,4 & 0,4 & 88,4 \\
\hline & & Mín. & 0,3 & 2,3 & 0,4 & 77,1 \\
\hline & & Média & 0,5 & 2,4 & 0,4 & 85,3 \\
\hline \multirow{5}{*}{ 柋 } & \multirow{5}{*}{$\begin{array}{l}\text { Campanha I } \\
\text { (nov 2008) } \\
\text { Campanha II } \\
\text { (mar 2009) }\end{array}$} & Máx. & 2,0 & 2,7 & 0,6 & 78,1 \\
\hline & & Mín. & 0,9 & 2,2 & 0,4 & 72,9 \\
\hline & & Máx. & 1,7 & 2,3 & 0,5 & 72,9 \\
\hline & & Mín. & 0,8 & 2,0 & 0,4 & 46,3 \\
\hline & & Média & 1,2 & 2,2 & 0,5 & 69,6 \\
\hline \multirow{5}{*}{$\begin{array}{l}\stackrel{0}{0} \\
\dot{\leftrightarrow} \\
\dot{q} \\
\dot{v}\end{array}$} & \multirow{5}{*}{$\begin{array}{l}\text { Campanha I } \\
\text { (nov 2008) } \\
\text { Campanha II } \\
\text { (mar 2009) }\end{array}$} & Máx. & 0,7 & 2,2 & 0,6 & 70,1 \\
\hline & & Mín. & 0,6 & 2,2 & 0,6 & 63,7 \\
\hline & & Máx. & 0,7 & 2,2 & 0,7 & 60,3 \\
\hline & & Mín. & 0,5 & 1,8 & 0,5 & 37,9 \\
\hline & & Média & 0,6 & 2,1 & 0,6 & 59,6 \\
\hline \multirow{5}{*}{ 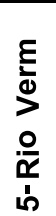 } & \multirow{5}{*}{$\begin{array}{l}\text { Campanha I } \\
\text { (nov 2008) } \\
\text { Campanha II } \\
\text { (mar 2009) }\end{array}$} & Máx. & 0,7 & 2,3 & 0,5 & 80,4 \\
\hline & & Mín. & 0,6 & 2,0 & 0,4 & 61,1 \\
\hline & & Máx. & 0,5 & 2,2 & 0,6 & 71,3 \\
\hline & & Mín. & 0,5 & 2,1 & 0,4 & 58,3 \\
\hline & & Média & 0,6 & 2,1 & 0,5 & 67,6 \\
\hline
\end{tabular}


de $643,6 \mathrm{~mm}$ de precipitação, enquanto na segunda campanha (março de 2009), o índice pluviométrico foi de $266,5 \mathrm{~mm}$. Quanto ao regime de ventos, ambas as campanhas foram conduzidas sob fraca influência deste agente.

A salinidade média na laguna variou entre 5,1 e 18,8 na coluna d'água e 5,2 e 19,2 na água de percolação do sedimento ao longo das duas campanhas (Tabela 2). A subárea 4-Beco apresentou a maior salinidade, assim como verificado anteriormente por Pereira (2004). O oxigênio dissolvido apresentou um padrão de variação menor entre as subáreas do que na mesma estação, entre os valores da coluna d'água e da água de percolação em todas as subáreas (Figura 2). Com relação à temperatura, a subárea 5-Rio Vermelho apresentou águas ligeiramente mais frias que as demais. Analisando estatisticamente as variáveis físico-químicas, verificaram-se diferenças significativas na distribuição espacial da salinidade (coluna d'água e percolação), pH (coluna d'água) e oxigênio (coluna d'água) entre as subáreas (considerando ambas as campanhas).

\section{Nutrientes}

Com relação aos nutrientes, não foram verificadas variações espaciais estatisticamente significativas nas concentrações de NID (nitrogenados inorgânicos dissolvidos) e de ortofosfato dissolvido entre as cinco subáreas (Figura 2). O único nutriente que permitiu diferenciá-las foi a sílica reativa, que apresentou valores superiores na área 2-Centrinho, considerando ambas as campanhas.

Comparando os resultados de nutrientes obtidos na coluna d'água com os limites recomendados pela Resolução n.357 do CONAMA (2005) para águas salobras classe 1 e pelos valores sugeridos por Aminot \& Chaussepied (1983) para águas estuarinas não poluídas, observou-se que o nitrogênio amoniacal, nitrito e a sílica reativa dissolvidos não se encontraram em concentrações excedentes aos limites em nenhuma das subáreas estudadas. Entretanto, o nitrato e ortofosfato dissolvidos determinados na segunda campanha apresentaram concentrações superiores ao limite estabelecido em quase todas as subáreas (Tabela 3). Em termos temporais, entre as campanhas de 2008 (novembro) e 2009 (março) observou-se uma tendência de redução do NID e aumento dos teores de ortofosfato ao longo das áreas rasas marginais (Figura 2).

\section{Coliformes Fecais}

Com relação às análises microbiológicas (indicadoras do aporte de esgotos domésticos), verificou-se concentração de coliformes fecais na coluna d'água superior aos limites propostos pela Resolução n. 274 do CONAMA (2000) (Tabela 3), em todas as subáreas na primeira campanha, com exceção da 1-Canto. As subáreas 4-Beco e 2-Centrinho apresen-

Tabela 2 - Valores máximos e mínimos dos parâmetros físico-químicos analisados em cada subárea da Lagoa da Conceição (CA= coluna d'água; APF= água de percolação de fundo).

\begin{tabular}{|c|c|c|c|c|c|c|c|c|c|c|}
\hline \multirow{2}{*}{\multicolumn{3}{|c|}{ Subárea x campanha }} & \multicolumn{2}{|c|}{ Salinidade } & \multicolumn{2}{|c|}{ Oxig. Dis. } & \multicolumn{2}{|c|}{ pH } & \multicolumn{2}{|c|}{ Temperatura } \\
\hline & & & $\mathrm{CA}$ & APF & $\mathrm{CA}$ & APF & $\mathrm{CA}$ & APF & CA & APF \\
\hline \multirow{4}{*}{$\stackrel{\stackrel{?}{\frac{L}{\pi}}}{J}$} & \multirow{2}{*}{$\begin{array}{l}\text { Campanha I } \\
\text { (nov 2008) }\end{array}$} & Máx. & 6,1 & 6,1 & 4,28 & 4,09 & 6,84 & 6,15 & 25,93 & 25,59 \\
\hline & & Mín. & 5,1 & 5,2 & 3,81 & 3,10 & 5,93 & 5,80 & 25,64 & 24,97 \\
\hline & \multirow{2}{*}{$\begin{array}{l}\text { Campanha II } \\
(\operatorname{mar} 2009)\end{array}$} & Máx. & 11,4 & 11,7 & 5,21 & 3,11 & 8,12 & 7,95 & 28,40 & 28,10 \\
\hline & & Mín. & 11,0 & 11,0 & 4,43 & 1,09 & 8,03 & 7,81 & 27,60 & 27,40 \\
\hline \multirow{4}{*}{ 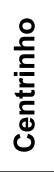 } & \multirow{2}{*}{$\begin{array}{l}\text { Campanha I } \\
\text { (nov 2008) }\end{array}$} & Máx. & 10,4 & 10,3 & 4,97 & 4,32 & 8,04 & 7,89 & 24,55 & 24,87 \\
\hline & & Mín. & 10,1 & 9,9 & 4,76 & 3,02 & 7,99 & 7,46 & 24,05 & 24,32 \\
\hline & \multirow{2}{*}{$\begin{array}{l}\text { Campanha II } \\
(\operatorname{mar} 2009)\end{array}$} & Máx. & 10,1 & 11,0 & 8,75 & 4,23 & 8,17 & 7,93 & 28,30 & 28,20 \\
\hline & & Mín. & 9,9 & 8,1 & 5,38 & 1,38 & 8,06 & 7,60 & 28,00 & 27,60 \\
\hline \multirow{4}{*}{ 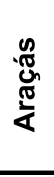 } & \multirow{2}{*}{$\begin{array}{l}\text { Campanha I } \\
\text { (nov 2008) }\end{array}$} & Máx. & 12,2 & 12,5 & 4,63 & 3,00 & 7,00 & 6,79 & 26,70 & 26,47 \\
\hline & & Mín. & 11,8 & 12,2 & 4,14 & 1,48 & 6,71 & 6,77 & 25,53 & 24,29 \\
\hline & \multirow{2}{*}{$\begin{array}{l}\text { Campanha II } \\
\text { (mar 2009) }\end{array}$} & Máx. & 18,8 & 18,8 & 6,51 & 1,89 & 7,96 & 7,92 & 28,20 & 28,00 \\
\hline & & Mín. & 18,7 & 18,8 & 6,36 & 0,48 & 7,75 & 7,87 & 27,70 & 27,90 \\
\hline \multirow{4}{*}{ : } & \multirow{2}{*}{$\begin{array}{l}\text { Campanha I } \\
\text { (nov 2008) }\end{array}$} & Máx. & 14,0 & 14,3 & 4,68 & 4,20 & 5,61 & 5,69 & 26,67 & 26,40 \\
\hline & & Mín. & 14,0 & 6,7 & 4,59 & 2,35 & 5,43 & 5,42 & 26,53 & 25,94 \\
\hline & \multirow{2}{*}{$\begin{array}{l}\text { Campanha II } \\
\text { (mar 2009) }\end{array}$} & Máx. & 18,1 & 19,2 & 7,30 & 2,23 & 7,98 & 7,59 & 26,70 & 26,60 \\
\hline & & Mín. & 18,0 & 18,2 & 6,60 & 1,31 & 7,51 & 7,49 & 26,40 & 26,30 \\
\hline \multirow{4}{*}{$\begin{array}{l}\xi \\
\frac{\xi}{\delta} \\
\frac{\partial}{\alpha}\end{array}$} & \multirow{2}{*}{$\begin{array}{l}\text { Campanha I } \\
\text { (nov 2008) }\end{array}$} & Máx. & 12,2 & 13,0 & 3,78 & 1,86 & 7,77 & 7,56 & 24,13 & 23,47 \\
\hline & & Mín. & 12,0 & 12,4 & 3,60 & 1,12 & 7,74 & 7,46 & 23,64 & 23,26 \\
\hline & \multirow{2}{*}{$\begin{array}{l}\text { Campanha II } \\
(\operatorname{mar} 2009)\end{array}$} & Máx. & 17,0 & 17,3 & 4,71 & 2,40 & 7,71 & 7,57 & 25,90 & 26,30 \\
\hline & & Mín. & 16,9 & 17,1 & 4,46 & 1,51 & 7,34 & 7,31 & 25,80 & 26,10 \\
\hline
\end{tabular}



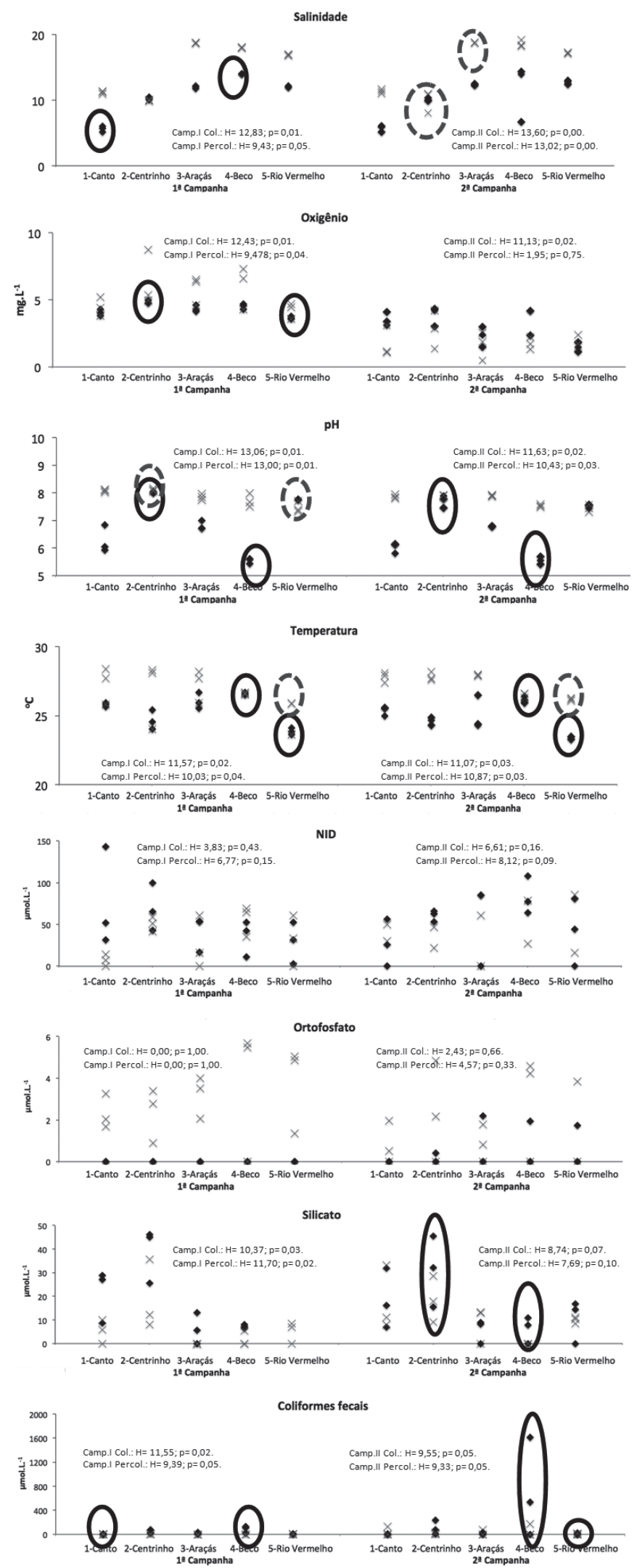

Figura 2 - Valores físico-químicos, nutrientes e coliformes fecais da coluna d'água e água de percolação do sedimento nas duas campanhas amostrais ao longo das subáreas rasas marginais da Lagoa da Conceição ( $\mathrm{H}=$ teste de Kruskal-Wallis; Camp.l= primeira campanha amostral; Camp.II= segunda campanha amostral; Col.= coluna d'água; Perc.= percolação; Destaque= subáreas estatisticamente diferenciadas pelo teste de Dunn; Campanha 1=>; Campanha 2=x.). 
Tabela 3 - Valores máximos e mínimos de nutrientes e coliformes fecais analisados em cada subárea da Lagoa da Conceição. Valores máximos e mínimos obtidos por Fonseca et al. (2002) e valores limites estabelecidos pelas resoluções CONAMA n. 274 (2000) e 357 (2005) e por Aminot \& Chaussepied (1983) (CA= coluna d'água; APF= água de percolação de fundo).

\begin{tabular}{|c|c|c|c|c|c|c|c|c|c|c|c|c|c|c|}
\hline \multirow{2}{*}{\multicolumn{2}{|c|}{ Subárea $x$ campanha }} & & \multicolumn{2}{|c|}{$\begin{array}{c}\text { Colif. } \\
\text { Fecais } \\
(\mathrm{NMP} / \mathrm{mL})\end{array}$} & \multicolumn{2}{|c|}{$\begin{array}{c}\text { N. Amoniacal } \\
\text { N-NH } \text { N }_{3,4} \\
\left(\mu \text { mol. }^{-1}\right)\end{array}$} & \multicolumn{2}{|c|}{$\begin{array}{c}\text { Nitrato } \\
\text { N-NO } \\
\left(\mu \mathrm{mol}_{3} \mathrm{~L}^{-1}\right)\end{array}$} & \multicolumn{2}{|c|}{$\begin{array}{c}\text { Nitrito } \\
\mathrm{N}-\mathrm{NO}_{2} \\
\left(\mu \mathrm{mol} \cdot \mathrm{L}^{-1}\right)\end{array}$} & \multicolumn{2}{|c|}{$\begin{array}{l}\text { Ortofosfato } \\
\text { PO }_{4} \\
\left(\mu \mathrm{mol} . \mathrm{L}^{-1}\right)\end{array}$} & \multicolumn{2}{|c|}{$\begin{array}{c}\text { Silicato } \\
\mathrm{SiO}_{2} \\
\left(\mu \mathrm{mol}^{-1}\right)\end{array}$} \\
\hline & & & $\mathrm{CA}$ & APF & $\mathrm{CA}$ & $\mathrm{APF}$ & $\mathrm{CA}$ & APF & $\mathrm{CA}$ & APF & $\mathrm{CA}$ & APF & $\mathrm{CA}$ & APF \\
\hline \multirow{4}{*}{ 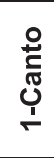 } & \multirow{2}{*}{$\begin{array}{l}\text { Campanha I } \\
\text { (nov 2008) }\end{array}$} & Máx. & 5 & 130 & 1,43 & 2,86 & 140,0 & 53,57 & 1,36 & 0,71 & ND & ND & 28,93 & 33,21 \\
\hline & & Mín. & 2 & 5 & 1,43 & 2,14 & 30,00 & 22,14 & ND & ND & ND & ND & 8,93 & 16,07 \\
\hline & \multirow{2}{*}{$\begin{array}{l}\text { Campanha II } \\
(\operatorname{mar} 2009)\end{array}$} & Máx. & 11 & 5 & ND & ND & 14,28 & 30,00 & ND & ND & 3,22 & 1,93 & 10,11 & 11,07 \\
\hline & & Mín. & $<2$ & 2 & ND & ND & ND & ND & ND & ND & 1,61 & ND & ND & 7,14 \\
\hline \multirow{4}{*}{ 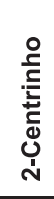 } & \multirow{2}{*}{$\begin{array}{l}\text { Campanha I } \\
\text { (nov 2008) }\end{array}$} & Máx. & 79 & 240 & 5,00 & 2,14 & 94,28 & 63,57 & 0,71 & 0,14 & ND & ND & 46,07 & 45,36 \\
\hline & & Mín. & 23 & 23 & 1,43 & 1,43 & 40,00 & 45,00 & ND & ND & ND & ND & 25,71 & 28,57 \\
\hline & \multirow{2}{*}{$\begin{array}{l}\text { Campanha II } \\
\text { (mar 2009) }\end{array}$} & Máx. & 7 & 13 & 2,14 & ND & 56,43 & 62,14 & ND & 0,71 & 3,22 & 4,84 & 35,71 & 17,86 \\
\hline & & Mín. & 4 & 4 & 1,43 & ND & 40,00 & 20,71 & ND & ND & 0,97 & 0,32 & 7,86 & 10,00 \\
\hline \multirow{4}{*}{ 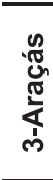 } & \multirow{2}{*}{$\begin{array}{l}\text { Campanha I } \\
\text { (nov 2008) }\end{array}$} & Máx. & 33 & 79 & 2,86 & 2,86 & 50,71 & 83,57 & 0,07 & 0,28 & ND & ND & 17,14 & 13,21 \\
\hline & & Mín. & 11 & 23 & 2,14 & 1,43 & 14,28 & 57,86 & ND & ND & ND & ND & 11,78 & 8,21 \\
\hline & \multirow{2}{*}{$\begin{array}{l}\text { Campanha II } \\
\text { (mar 2009) }\end{array}$} & Máx. & $<2$ & 2 & ND & 3,57 & 60,71 & 12,86 & ND & ND & 3,87 & 2,26 & ND & 13,21 \\
\hline & & Mín. & $<2$ & $<2$ & ND & ND & ND & ND & ND & ND & 1,93 & 0,64 & ND & ND \\
\hline \multirow{4}{*}{ 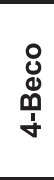 } & \multirow{2}{*}{$\begin{array}{l}\text { Campanha I } \\
\text { (nov 2008) }\end{array}$} & Máx. & 130 & 1610 & 1,43 & 2,14 & 50,71 & 104,3 & 0,28 & 1,43 & ND & ND & 13,21 & 10,71 \\
\hline & & Mín. & 21 & 170 & 1,43 & 1,43 & 9,28 & 75,00 & ND & 0,28 & ND & ND & ND & ND \\
\hline & \multirow{2}{*}{$\begin{array}{l}\text { Campanha II } \\
\text { (mar 2009) }\end{array}$} & Máx. & 2 & 2 & 2,14 & 3,57 & 68,57 & 60,71 & ND & 0,71 & 5,81 & 4,52 & 5,36 & ND \\
\hline & & Mín. & $<2$ & $<2$ & ND & ND & 33,57 & 27,14 & ND & ND & ND & 1,93 & ND & ND \\
\hline \multirow{4}{*}{$\begin{array}{l}\frac{\varepsilon}{0} \\
\frac{0}{\alpha} \\
\frac{0}{10}\end{array}$} & \multirow{4}{*}{$\begin{array}{l}\text { Campanha I } \\
\text { (nov 2008) } \\
\text { Campanha II } \\
\text { (mar 2009) }\end{array}$} & Máx. & 11 & 23 & 2,86 & 4,28 & 50,00 & 82,14 & 0,50 & 0,71 & ND & ND & 8,21 & 16,78 \\
\hline & & Mín. & 5 & 2 & 2,14 & 2,86 & ND & 40,00 & ND & ND & ND & ND & 6,43 & 11,07 \\
\hline & & Máx. & 8 & 13 & 2,14 & 2,14 & 60,00 & 28,57 & ND & ND & 5,16 & 6,13 & 8,57 & 10,36 \\
\hline & & Mín. & 8 & 2 & ND & ND & ND & ND & ND & ND & 1,29 & 1,61 & ND & ND \\
\hline \multirow{2}{*}{\multicolumn{2}{|c|}{ Fonseca et al. (2002) }} & Máx. & - & - & 11,43 & - & 23,57 & - & 0,57 & - & 0,64 & - & 20,71 & - \\
\hline & & Mín. & - & - & 0,21 & - & 2,14 & - & 0,14 & - & 0,06 & - & 1,78 & - \\
\hline \multicolumn{3}{|c|}{ CONAMA (2005) } & 8 & - & 28,57 & - & 28,57 & - & 5,00 & & & & & \\
\hline \multicolumn{3}{|c|}{$\begin{array}{l}\text { Aminot \& Chaussepied } \\
(1983)\end{array}$} & & & & & $\begin{array}{l}\text { Máx } \\
15,00\end{array}$ & - & 1,00 & - & 1,00 & - & 150,00 & \\
\hline
\end{tabular}

taram as maiores concentrações de coliformes fecais (valores máximos e mínimos de 130 e $21 \mathrm{NMP} / \mathrm{mL}$ na subárea 4-Beco e 79 e $23 \mathrm{NMP} / \mathrm{mL}$ na subárea 2-Canto), sendo que a primeira foi a única que se diferenciou estatisticamente das demais.

\section{Integração espaço-temporal}

Os resultados obtidos a partir da Análise de Componentes Principais mostraram maior diferenciação no comportamento hídrico do corpo lagunar entre as duas campanhas amostrais (distribuídas em lados opostos dos gráficos) do que entre as subáreas estudadas (Figura 3).

A primeira campanha, realizada antes do verão e influenciada pela alta pluviosidade, caracterizouse pelos maiores teores de sílica reativa, nitrogênio inorgânico dissolvido e coliformes fecais (Figura 3). Já a segunda campanha diferenciou-se da anterior pelo aumento do oxigênio dissolvido e pelas elevadas concentrações de ortofosfato.

Em relação ao comportamento das subáreas, as temperaturas da coluna d'água e da água de percolação de fundo diferenciaram a subárea 5-Rio Vermelho, que apresentou temperaturas mais baixas que as demais. Já a subárea 2-Canto diferenciou-se das demais pelos teores maiores de sílica reativa e de nitrogenados inorgânicos dissolvidos (NID) (Figura 2).

\section{DISCUSSÃO}

A contribuição de sedimentos mais finos na área 2-Centrinho pode estar indicando uma maior degradação antrópica da bacia hidrográfica neste setor. Áreas urbanizadas e/ou com solo exposto são mais susceptíveis ao carreamento de partículas finas do sedimento para a laguna. Um exemplo disso foi o estudo histórico geoquímico e de sedimento na Baía de Guanabara, onde foi verificado um incremento de sedimento fino a partir da década 70 , coincidindo com o crescimento urbano e com a devastação da cobertura vegetal das áreas de mangue do entorno (Borges et al., 2009). 


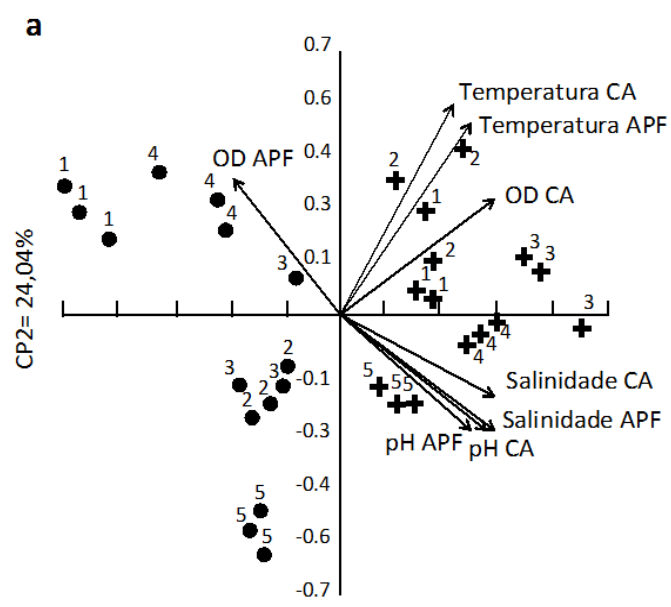

- 1a Campanha

+2a Campanha

$\mathrm{CP} 1=46,78 \%$

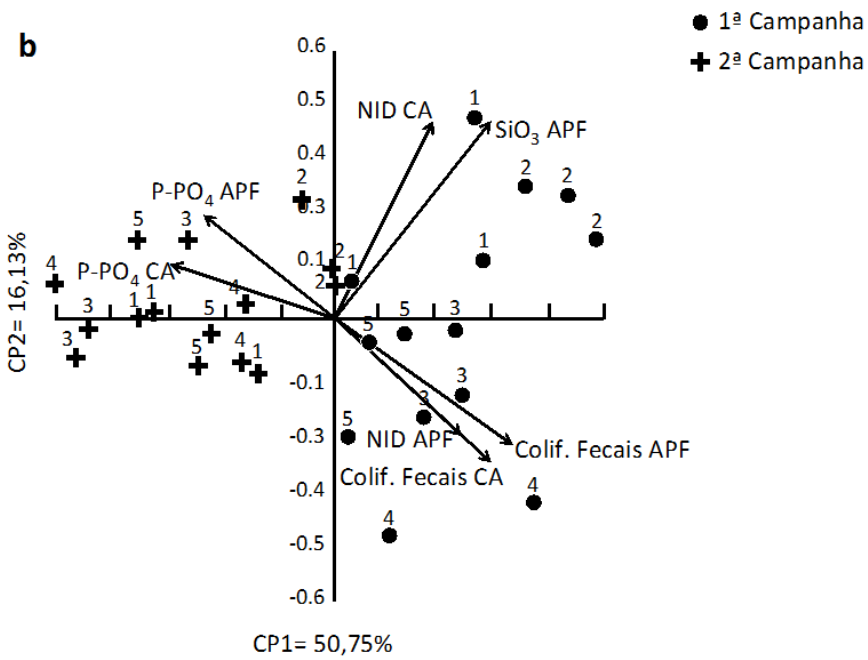

Figura 3 - Análise dos Componentes Principais mostrando a diferenciação espacial e temporal das áreas rasas marginais da Lagoa da Conceição quanto às variações físico-químicas (a) e quanto aos indicadores de enriquecimento inorgânico e contaminação fecal (b). Números relacionados às amostras em cada área amostral (1-Canto; 2-Centrinho; 3-Araçás; 4-Beco; 5-Rio Vermelho). (CA= Coluna de Água; $\mathrm{APF}=$ Água de Percolação de Fundo; $\mathrm{OD}=$ Oxigênio Dissolvido; NID= Nitrogenados Inorgânicos Dissolvidos; Colif.Fecais= Coliformes Fecais; CP1= Componente Principal 1; CP2= Componente Principal 2).

Relacionado à diferença na distribuição dos teores de matéria orgânica nos sedimentos da Lagoa, estudos anteriores demonstraram que a maior porcentagem está localizada nas áreas mais profundas. Nestes trechos foram encontrados teores orgânicos de até 40\% (Gré \& Horn Filho, 1999; Rudorff et al., 2005). Esta diferença composicional entre as áreas rasas $e$ mais profundas deve-se provavelmente à maior hidrodinâmica das primeiras, fator que dificulta a deposição de sedimentos finos e a adsorção de compostos orgânicos. No caso dos bancos arenosos marginais estudados neste trabalho, todos apresentaram valores bem baixos, mas a subárea 3-Araçás diferenciou-se das demais por conter o dobro dos teores encontrados nas demais $(1,2 \pm 0,5 \%)$. Este resultado não pode ser explicado apenas pelas condições hidrodinâmicas, visto esta ser uma área sob influência das ondas geradas pelos ventos de Nordeste, o que dificulta o acúmulo de sedimentos finos. Acredita-se assim que o aumento nos teores orgânicos pode estar associado à densa ocupação urbana do entorno e ao aporte oriundo de um córrego canalizado nas proximidades da área de coleta.

As variáveis físico-químicas apresentaram valores significativamente diferentes entre as campanhas realizadas. Estes resultados podem ser decorrentes do alto índice pluviométrico ocorrido durante o mês anterior à primeira campanha, o qual ocasionou valores de salinidade e $\mathrm{pH}$ mais baixos. O oxigênio dissolvido da coluna d'água também apresentou valores superiores na segunda campanha, enquanto que na água de percolação esta mesma variável apresentou valores similares. É possível que a concentração de oxigênio dissolvido da coluna d'água tenha aumentado após o verão devido à maior atividade fotossintética na segunda campanha, estimulada por sua vez pelo aumento de 
nutrientes disponíveis. Todavia, outros fatores, como variabilidade diária e não apenas sazonal, tais como o horário das coletas, luminosidade e grau de agitação das águas podem também ter sido responsáveis por estas variações entre as campanhas.

Com relação aos teores de nutrientes, estudos anteriores mostraram que nas áreas mais densamente urbanizadas do entorno da Lagoa, as concentrações de silicato, nitrito e nitrato (valores mínimo e máximo de $1,64 \pm 3,14 \mu \mathrm{M}$ e $34,44 \pm 5,42 \mu \mathrm{M} ; 0,03 \pm 0,14 \mu \mathrm{M}$ e $0,25 \pm 0,07 \mu \mathrm{M} ; 0,04 \pm 0,18 \mu \mathrm{M}$ a $2,54 \pm 3,01 \mu \mathrm{M}$, respectivamente) foram maiores em relação às áreas com menor influência da drenagem urbana (Fonseca, 2006). Os resultados obtidos mostraram essa mesma tendência para os teores sílica reativa na área 2-Centrinho, o que pode estar indicando um incremento de água doce na Lagoa neste ponto provindo dos canais de drenagem da bacia hidrográfica. Entretanto, as concentrações superiores podem ser decorrentes da remobilização do sedimento arenoso de fundo, devido à ação das ondas do quadrante Sul. $\mathrm{O}$ alto índice pluviométrico ocorrido anteriormente à primeira campanha pode ter sido o fator desencadeador da maior concentração de sílica reativa nesta em relação à segunda campanha. $\mathrm{O}$ incremento no aporte de água doce no corpo lagunar, associado à lixiviação das margens pelas fortes chuvas, pode ter resultado em concentrações maiores de sílica transportada pelos canais de drenagem da bacia hidrográfica (Fonseca, 2006).

Fonseca (2004) revelou resultados similares para o nitrogênio amoniacal, nitrato e nitrito dissolvidos, onde sua redução foi associada a um maior consumo desses nutrientes no verão, devido o aumento da demanda fitoplanctônica. No caso do ortofosfato, na primeira campanha seus valores estiveram próximo a zero, enquanto na segunda houve um aumento generalizado em suas concentrações (média de $2,58 \pm 1,93 \mu \mathrm{M})$. Isso pode ter ocorrido devido ao aumento das atividades turísticas na Lagoa durante os meses de janeiro e fevereiro, fator que ocasiona um aumento de despejos de esgotos domésticos e comerciais. Outra suposição seria a liberação de fósforo do sedimento com o aumento da salinidade por meio de um choque iônico que disponibiliza esse nutriente adsorvido no sedimento para a água (Santos et al., 2007). Esse efeito foi observado por Baumgarten \& Niencheski (2010) na Lagoa dos Patos, onde períodos de entrada da água marinha no estuário promoveram a advecção do fosfato das camadas superficiais do sedimento para a coluna d'água. A relação inversa entre os teores de oxigênio dissolvido e ortofosfato não foi verificada. Quando condições de hipoxia prevalecem, o conteúdo de ortofosfato tende a se elevar na coluna de água devido à solubilização (Fontes, 2004).
O índice pluviométrico acumulado no mês também pode ter ocasionado as maiores densidades de coliformes fecais na primeira campanha. As chuvas intensas saturaram o solo, promoveram uma elevação do lençol freático e causaram em algumas localidades o transbordamento das fossas sépticas. Esta situação facilitou o carreamento de esgotos domésticos (precariamente ou até mesmo não tratado) para o interior da Lagoa. Já na segunda campanha, considerando o limite para balneabilidade de até $8 \mathrm{NMP} / 1 \mathrm{~mL}$, a concentração de coliformes fecais foi superior a este padrão apenas na área 1-Canto. Esses resultados confirmam a contaminação das águas lagunares por esgoto doméstico e sugerem que o risco aumenta, sobretudo após eventos de maior pluviosidade.

\section{CONCLUSÃO}

Os resultados sedimentológicos e hidroquímicos obtidos em duas condições ambientais distintas refletiram o gradiente de confinamento das águas marinhas, os aportes fluviais, os aportes orgânicos de fontes antrópicas e também a variação do índice pluviométrico. No final de novembro de 2008 , antes do início da temporada de verão e após um período de alta pluviosidade, o corpo lagunar apresentou altas concentrações de nitrogenados e de coliformes fecais. Já em março de 2009, logo após o fim da temporada e sob uma condição mais seca, constatou-se um aumento da salinidade, do oxigênio dissolvido e, sobretudo do ortofosfato. Este elemento, que havia sido detectado apenas em concentrações muito baixas antes do verão, ocorreu com concentrações acima dos limites estabelecidos pela legislação brasileira em todo o corpo lagunar no mês de março. Acredita-se que esta mudança seja decorrente do maior aporte de esgotos domésticos durante a temporada, consequência do aumento no fluxo de turistas e da taxa de ocupação dos bairros em torno do corpo lagunar. Apesar disso, estes resultados sugerem que os agentes modificadores da qualidade das águas nas áreas rasas avaliadas são pontuais e possuem papel secundário em relação às mudanças temporais induzidas por condições climáticas e oceanográficas.

Este estudo também possibilitou diferenciar as subáreas em função de alterações hidroquímicas e sedimentológicas locais. Duas subáreas apresentaram-se diferentes quanto à influência marinha na laguna: a subárea 4-Beco e a subárea 3-Araçás. Ambas encontram-se próximas ao Canal da Barra, sendo, portanto, favorecidas pela renovação das águas marinhas. Verificou-se ainda a diferenciação de duas outras subáreas: 1-Canto, por suas concentrações superiores de matéria orgânica total nos 
sedimentos superficiais e a área 2-Centrinho, por seus sedimentos mais finos e suas concentrações elevadas de sílica reativa.

\section{REFERÊNCIAS}

American Public Health Association (APHA). 1992. Standard Methods for the Examination of Water and Wastewater. $18^{\text {th }}$ edition. American Public Health Association, Washington, 1100p.

Aminot, A. \& Chaussepied, M. 1983. Manuel des analyses chimiques en milieu marin. CNEXO, Brest, 395p.

Baumgarten, M.G.Z.; Rocha, J.M.B. \& Niencheski, L.F.H. 1996. Manual de análises em Oceanografia Química. Ed. FURG, Rio Grande, 132p.

Baumgarten. M.G.Z. \& Niencheski, L.F.H. 2010. A coluna sedimentar como reservatório e fonte de nutrientes em enseadas estuarinas. Tropical Oceanogr. 38(1): 88-104.

Borges, A.C.; Sanders, C.J.; Santos, H.L.R.; Araripe, D.R.; Machado, W. \& Patchineelam, S.R. 2009. Eutrophication history of Guanabara Bay (SE Brazil) recorded by phosphorus fluz to sediments from a degraded mangrove area. Mar. Poll. Bull. 58: $1739-1765$.

Carloni, F.B.B.A; Wasserman, J.C.; Pereira, L.F.M. \& Moreira, M.F. 2010. Mudanças na qualidade da água de uma laguna do leste fluminense, geradas pela abertura permanente de conexão com o mar. Geochi. Brasil. 24(1): 29-40.

Conselho Nacional do Meio Ambiente (CONAMA). 2000. Resolução $n^{\circ} 274$, de 29 de novembro de 2000.

Conselho Nacional do Meio Ambiente (CONAMA). 2005. Resolução n 357 de 17 de março de 2005. DOU no 53 de 30 de julho. Revoga da Resolução CONAMA n 20 de 1986.

Cotovicz Jr, L.C.C.; Brandini, N.; Knoppers, B.A.; Mizerkowski, B.D.; Sterza, J.M.; Ovalle, A.R.C. \& Medeiros, P.R.P. 2013. Assessment of the trophic status of four coastal lagoons and one estuarine delta, eastern Brazil. Environ. Monit. Assess. 185: 3297-3311.

Folk, R.I. \& Ward, W.C. 1957. Brazos river bar: study of the significance of grain size parameters. J. Sed. Petrol. 17: 3-27.

Fonseca, A.; Braga, E.S. \& Eichler, B.B. 2002. Distribuição espacial dos nutrientes inorgânicos dissolvidos e da biomassa fitoplanctônica no sistema pelágico da Lagoa da Conceição, Santa Catarina, Brasil (Setembro, 2000). Atlântica. 24(2): 69-83.

Fonseca, A. 2004. Variação sazonal e espacial das características hidroquímicas, dos fluxos de nutrientes e do metabolismo na interface águasedimento da Lagoa da Conceição (SC, Brasil). Tese de Doutorado. Universidade de São Paulo. 200p.

Fonseca, A. 2006. Efeito da drenagem urbana nas características físico-químicas e biológicas da água superficial na Lagoa da Conceição (Florianópolis, SC, Brasil). Biotemas. 19(2): 7-16.

Fonseca, A. \& Braga, E.S. 2006. Temporal dynamic of the dissolved nutrients and the eutrophization processes in a Southern Brazilian Coastal Lagoon, Conceição Lagoon. J. Coastal Res., Special Issue. 39: 1229-1233.

Fontes, M.L.S. 2004. Breve Estudo Espaço-Temporal e de Impacto do Feriado de Carnaval e de Corpus Christi sobre Variáveis Ambientais nas Águas da Lagoa da Conceição - Florianópolis. Dissertação de Mestrado. Universidade Federal de Santa Catarina. 195p.

Fontes, M.L.S. \& Abreu, P.C. 2009. Spatiotemporal variation of bacterial assemblages in a shallow subtropical coastal lagoon in Southern Brazil. Microb. Ecol. 58: 140-152.

Fontes, M.L.S.; Suzuki, M.T.; Cottrell, M.T. \& Abreu, P.C. 2011. Primary production in a subtropical stratified coastal lagoon - contribution of anoxygenic phototrophic bacteria. Microb. Ecol. 61: 223-237.

Food \& Drug Administration (FDA). 1984. Bacteriological analytical manual. $6^{\text {th }}$ ed. Association of Official Analytical Chemists, Arlington. 614p.

Fries, J. 1971. Análisis de Trazas. Métodos Fotométricos Comprobado. Ed. Merck, Darmstad, 184p.

Gré, J.C.R. \& Horn Filho, N.O. 1999. Caracterização textural dos sedimentos de fundo da Lagoa da Conceição, Ilha de Santa Catarina, SC, Brasil. In: Sierra De Ledo, B. \& Ej Soriano-Sierra (eds.) O Ecossistema da Lagoa da Conceição. NEMAR/ CCB/UFSC. SDM/FEPEMA. 25-34pp.

Gross, M.G. 1971. Carbon determination. In: Carver, R.E. (ed.) Procedures in Sedimentology Petrology. Wiley Interscience, New York. 49-94pp.

Kjerfve, B. 1994. Coastal lagoons processes. In: Kjerfve, B. (ed.). Coastal lagoon processes. Elsevier Science Publishers, Amsterdam. 1-7pp.

Knoppers, B.; Opitz, S.S.; Souza, M.M. \& Miguez, C.F. 1984. The spatial distribution of particulate organic matter and some physical and chemical water properties in Conceição Lagoon, Santa Catarina, Brazil. Arch. Biol. Tecnol. 27(1): 59-77.

Koroleff, K. 1969. Determination of phosphorus. In: Grasshoff, K.; Erhardt, M. \& Kremling, K. (eds.) Methods of seawater analysis. $2^{\text {nd }}$ edition. Verlag Chemie, Weinhein. 125-139pp. 
Kovach, W.L. 1999. MVSP: A multivariate statistical package for windows. Version 3.1. Disponível em: <http://www.kovcomp.co.uk/mvsp/>.

Martini, L.C.P.; Mattos, D.S.; Barbosa, D.F.P. \& Aib Rech. 2006. Uso de sensoriamento remoto orbital para avaliação da distribuição espacial de clorofila a na Lagoa da Conceição - Florianópolis, SC. Eng. Sanit. Amb. 11(4): 318-324.

Niencheski, L.F.H.; Baumgarten, M.G.Z. \& WallnerKersanach, M. 2006. Caracterização ambiental: hidroquímica e sedimentologia. In: Lana, P.C., Bianchini, A.; Ribeiro, C.; Niencheski, L.F.H.; Fillmann, G. \& Santos, C.S.G. (orgs.) Avaliação Ambiental de Estuários Brasileiros: Diretrizes Metodológicas. Museu Nacional, Rio de Janeiro. 14-62pp.

Pereira, MLM. 2004. Estudo da dinâmica das águas do Canal da Barra, Barra da Lagoa - Florianópolis, SC. Dissertação de Mestrado. Universidade Federal de Santa Catarina. 148p.

Pinto Filho, J.L.O.; Santos, E.G. \& Souza, M.J.J.B. 2012. Proposta de índice de qualidade de água para a Lagoa do Apodi, RN, Brasil. Holos. 28(2): 69-76.

Rudorff, F.M.; Bonetti, J.; Peixoto, J.R.V.; Oliveira, U.R. \& Bonetti, C. 2005. Setorização do subsistema sul da Lagoa da Conceição, Santa Catarina. Braz. J. Aquat. Sci. Technol. 9(2): 49-56.

Santos, I.R.; Baisch, P.; Lima, G.; Mirlean, N.; Griep, G. \& Silva-Filho, E.V. 2004. Análise estatística multivariada de parâmetros geoquímicos em sedimentos do estuário da Laguna dos Patos. Geochim. Brazil. 18(1): 38-45.
Santos, M.L.S.; Muniz, K.; Feitosa, F.A.N. \& Neto, B.B. 2007. Estudos das diferentes formas de fósforo nas águas da plataforma continental do Amazonas. Quím. Nova. 30(3): 569-573.

Sierra de Ledo, B. 1999. Lagoa da Conceição: uma abordagem ecológica. In: Sierra de Ledo, B. \& Soriano-Sierra, E.J. (eds.) O Ecossistema da lagoa da Conceição. NEMAR/CCB/UFSC. SDM/ FEPEMA, Florianópolis. 343-357pp.

Statsoft, I. 2004. Statistica: data analysis software system. Version 7. Disponível em: <http://www. statsoft.com/>.

Suguio, K. 1973. Introdução à sedimentologia. Edgard Blucher, São Paulo, 317p.

Valentin, J.P. 2000. Ecologia numérica - Uma introdução à análise multivariada de dados ecológicos. Editora Interciência, Rio de Janeiro, $117 p$.

Vieira, J.S. \& Henkes, J.A. 2013. Uma análise nos impactos ambientais causados na Lagoa da Conceição pelo despejo de efluentes. Rev. Gest. Sust. Ambient. 2(2): 309-337.

Zar, J.H. 1998. Biostatistical Analysis. $4^{\text {th }}$ edition. Prentice Hall, Englewood Cliffs, 929p. 